\title{
Evaluation of the Quantitative Expression and Correlation between Follicle Stimulating Hormone (FSH) and Luteinizing Hormone (LH) During Follicular phase in Primary Infertile Women of Reproductive Age
}

\author{
*Arome Solomon Odiba ${ }^{1}$, Parker Elijah Joshua ${ }^{2}$, Chimere Young Ukegbu ${ }^{2}$, \\ Iruoghene Onosakponome ${ }^{2}$ \\ ${ }^{I}$ Department of Biochemistry, University of Jos, Plateau State, Nigeria \\ ${ }^{2}$ Department of Biochemistry, University of Nigeria, Nsukka, Enugu State, Nigeria
}

\begin{abstract}
We determined the serum levels of FSH and LH in primary infertile women of reproductive age as well as the physiological correlation between these gonadotropins. This investigation was carried out at the Jos University Teaching Hospital (JUTH), Nigeria. The sample size is made up of seventy (70) women of reproductive age, falling within the range of 25-34 years, categorized into control $(n=35)$ and primary infertile $(n=35)$ certified as primary infertile by a gynecologist and referred for infertility investigation. A fasting morning blood sample was obtained from each of the patients during the follicular phase of the cycle for the investigation. FSH and LH serum levels were determined by enzyme-linked immunosorbent assay (ELISA) methods. When the FSH serum levels of the infertile women are compared to that of the control group statistically, it shows a statistically significantly higher serum FSH [FSH mean $\pm S D, 12.88 \pm 13.11(p<0.05)]$ in the infertile group than the control group. LH serum levels is higher in the infertile group than in the control group as well [mean \pm SD 9.95 $\pm 5.97(p<0.05)] .17 .14 \%$ had FSH serum levels below $(B)$ the normal range of expected values, $45.71 \%$ had serum levels within (W) normal range, and $37.14 \%$ had serum levels above (A) the normal range of expected values. For LH, $2.86 \%$ had LH serum levels below the normal range of expected values, $57.14 \%$ had serum levels within normal range, and $40 \%$ had serum levels above the normal range of expected values. Analysis of the physiological correlation between FSH and LH values for the infertile group shows that they are significantly correlated, $r=0.53, p<0.01 .34 .3 \%$ of the patients had both serum levels of FSH and LH within the normal limits (3.0-12.0 and 0.5-10.5 mlu/L respectively).In 2.9\% of the cases, both FSH and $L H$ serum levels are below the normal range of expected values (2.9\%).
\end{abstract}

Keywords: gonadotropins, hormones, Infertility, ovulation, primary.

\section{Introduction}

Infertility primarily refers to the inability of an individual to contribute to conception. Infertility may also refer to the inability of a woman to carry a pregnancy to full term [1]. Gynaecologists, having established that the male partner is fertile, consider a woman to be infertile if the woman has not conceived after twelve months of contraceptive free intercourse, if the female is under the age of 34, or the woman has not conceived after six months of contraceptive free intercourse if the female is over the age of 35 [2]. Primary infertility describes a state in which a woman has never been able to conceive [3]. Between 8 and 12 percent of couples around the world have difficulty conceiving a child at some point in their lives, and in some areas, the figure reaches one-third or more [4]. A world health organization (WHO) study of 5,800 infertile couples seeking help at 33 medical centers in 22 developed and developing countries-found that cases where the female partner is solely responsible for the infertility accounted for between 25 to 37 percent of infertility worldwide (with larger proportions in sub-Saharan Africa and Southeast Asia), cases where the male partner is solely responsible for the infertility accounted for about 8 to 22 percent, and cases where both the female and male partner are responsible for the infertility accounted for between 21 to 38 percent [5].

According to literature, infertility seems to be a multidimensional health issue which occurs not only due to health problems related to the fallopian tubes, the ovaries, and the endometrium, but it may also be a result of the choices imposed by the modern lifestyle, like the higher average age of people who get married, stress, non-conducive legal framework for assisted reproduction, etc. The causes of female infertility are reproductive hormonal disorders, problems in the fallopian tubes and the uterus, disorders of menstruation, sexual disorders, age and ovarian failure [6].

Amongst the many factors that account for primary infertility in women are the quantitative hormonal abnormalities in Follicle Stimulating Hormone (FSH) and luteinizing hormone (LH). FSH is a key hormone of mammalian reproduction that is necessary for gonadal development and maturation at puberty and for gamete 
production during the reproductive phase of life [7]. FSH is a member of the glycoprotein hormone family that also includes LH, HCG, and TSH. Follicle-stimulating hormone (FSH) is critical for ovarian folliculogenesis in female fertility. FSH plays a key role in antral follicle development and, in combination with luteinizing hormone (LH), stimulates preovulatory follicular growth [8]. In females, an acute rise of LH ("LH surge") triggers ovulation and development of the corpus luteum. The pituitary gland secretes FSH and(LH) in a pulsatile manner in response to gonadotropin releasing hormone $(\mathrm{GnRH})$. Most of the information available concerning the fluctuations of follicle-stimulating hormone and Luteinizing hormone in human subjects has been gained through bioassay of serum. This present investigation evaluates the hormonal profile of infertile women of reproductive age. The aim of the study was to estimate the mean value of FSH and LH serum levels in infertile women as compared to the control group as well as the physiological correlation between FSH and LH levels, the knowledge of which will brace scientists more in directing their energy towards the area that is actually most responsible for infertility.

\subsection{Study Subjects}

\section{Procedure For Research}

This investigation was carried out at the Jos University Teaching Hospital, University of Jos, Nigeria. The data was obtained from 70 women of reproductive age, categorized into control $(n=35)$, primary infertile $(n=35)$ certified as primary infertile by a gynecologist and referred for infertility investigation. The inclusion criteria for the selection of cases were diagnosis of secondary and primary infertility, age between 25-34 years and duration of marriage more than one year. The exclusion criteria that were adopted during case selection were male factor infertility and amongst the female factors were tubal factor, any congenital anomaly of the urogenital tract, or any obvious organic lesion [9]. The group of infertile women consisted of patient with menstrual cycle lasting between 28-30 days and with ovulation period between the $12^{\text {th }}$ and $16^{\text {th }}$ day of the cycle.

\subsection{Collection of Sample}

A fasting morning blood sample was obtained from each of the patients during the follicular phase of the cycle by venipuncture between day 5 and 10 of the menstrual cycle, into a plain redtop venipuncture tube without additives or anti-coagulants and allowed to clot.

\subsection{Procedures}

The blood was allowed to clot and the serum was decanted for analysis of the biochemical parameter. Hemolysis sera were discarded and a fresh specimen was obtained. The serum was stored between $2-8^{\circ} \mathrm{C}$ and assays were completed within three days. FSH and LH serum levels were estimated by Immuno enzymatic assay by ELISA Reader. The kits were obtained from Fortress Diagnostic Limited, United Kingdom, Northern Ireland [10].

\subsection{Biochemical parameters}

Each of the samples was investigated for serum levels of FSH and LH.

\subsection{Statistical Analysis}

The descriptive characteristics of the group variables were expressed as mean values and standard deviation. Comparison of the Mean values between the groups was done using unpaired t-test, Significance level was taken as $\mathrm{P}<0.05$. Statistical analysis was done using IBM SPSS version 20 and MS-excel.

\subsection{Results}

\section{Experimental Results And Discussion}

Table 1: serum levels of FSH and LH for control group

\begin{tabular}{|c|c|c|c|c|c|c|c|}
\hline $\begin{array}{l}\text { Patient(control) } \\
\text { I.D }\end{array}$ & Cycle phase & $\begin{array}{l}\text { FSH normal range } \\
(\mathrm{ml} \mu / \mathrm{L})\end{array}$ & $\mathrm{FSH}(\mathrm{ml} \mu / \mathrm{L})$ & R.INF & $\begin{array}{l}\text { LH normal Range } \\
(\mathrm{ml} \mu / \mathrm{L})\end{array}$ & $\mathrm{LH}(\mathrm{ml} \mu / \mathrm{L})$ & R.INF \\
\hline 01 & FP & $3.0-12.0$ & 6.4 & $\mathrm{~W}$ & $0.5-10.5$ & 0.4 & $\mathrm{~B}$ \\
\hline 02 & FP & $3.0-12.0$ & 8.3 & W & $0.5-10.5$ & 0.9 & W \\
\hline 03 & FP & $3.0-12.0$ & 12.3 & A & $0.5-10.5$ & 10.0 & $\mathrm{~W}$ \\
\hline 04 & FP & $3.0-12.0$ & 5.8 & $\mathrm{~W}$ & $0.5-10.5$ & 0.7 & $\mathrm{~W}$ \\
\hline 05 & FP & $3.0-12.0$ & 3.6 & $\mathrm{~W}$ & $0.5-10.5$ & 1.8 & $\mathrm{~W}$ \\
\hline 06 & $\mathrm{FP}$ & $3.0-12.0$ & 9.5 & $\mathrm{~W}$ & $0.5-10.5$ & 7.2 & $\mathrm{~W}$ \\
\hline 07 & FP & $3.0-12.0$ & 4.0 & $\mathrm{~W}$ & $0.5-10.5$ & 10.8 & $\mathrm{~A}$ \\
\hline 08 & FP & $3.0-12.0$ & 4.8 & $\mathrm{~W}$ & $0.5-10.5$ & 10.5 & $\mathrm{~W}$ \\
\hline 09 & FP & $3.0-12.0$ & 12.4 & A & $0.5-10.5$ & 4.4 & $\mathrm{~W}$ \\
\hline 10 & FP & $3.0-12.0$ & 9.9 & $\mathrm{~W}$ & $0.5-10.5$ & 6.5 & $\mathrm{~W}$ \\
\hline 11 & FP & $3.0-12.0$ & 3.1 & $\mathrm{~W}$ & $0.5-10.5$ & 13.2 & A \\
\hline 12 & FP & $3.0-12.0$ & 3.3 & $\mathrm{~W}$ & $0.5-10.5$ & 7.8 & $\mathrm{~W}$ \\
\hline 13 & FP & $3.0-12.0$ & 8.5 & $\mathrm{~W}$ & $0.5-10.5$ & 6.3 & $\mathrm{~W}$ \\
\hline
\end{tabular}


Evaluation of the Quantitative Expression and Correlation between Follicle Stimulating Hormone

\begin{tabular}{|c|c|c|c|c|c|c|c|}
\hline 14 & FP & $3.0-12.0$ & 2.9 & $\mathrm{~B}$ & $0.5-10.5$ & 9.1 & $\mathrm{~W}$ \\
\hline 15 & FP & $3.0-12.0$ & 8.3 & $\mathrm{~W}$ & $0.5-10.5$ & 12.0 & $\mathrm{~A}$ \\
\hline 17 & FP & $3.0-12.0$ & 3.1 & $\mathrm{~W}$ & $0.5-10.5$ & 0.7 & W \\
\hline 19 & FP & $3.0-12.0$ & 4.4 & $\mathrm{~W}$ & $0.5-10.5$ & 0.5 & $\mathrm{~W}$ \\
\hline 20 & FP & $3.0-12.0$ & 8.9 & $\mathrm{~W}$ & $0.5-10.5$ & 0.9 & $\mathrm{~W}$ \\
\hline 21 & FP & $3.0-12.0$ & 12.3 & $\mathrm{~A}$ & $0.5-10.5$ & 3.7 & $\mathrm{~W}$ \\
\hline 23 & FP & $3.0-12.0$ & 3.9 & $\mathrm{~W}$ & $0.5-10.5$ & 10.4 & W \\
\hline 24 & FP & $3.0-12.0$ & 8.2 & $\mathrm{~W}$ & $0.5-10.5$ & 7.3 & $\mathrm{~W}$ \\
\hline 25 & FP & $3.0-12.0$ & 8.9 & $\mathrm{~W}$ & $0.5-10.5$ & 4.5 & $\mathrm{~W}$ \\
\hline 26 & FP & $3.0-12.0$ & 10.1 & $\mathrm{~W}$ & $0.5-10.5$ & 2.2 & $\mathrm{~W}$ \\
\hline 27 & FP & $3.0-12.0$ & 8.3 & $\mathrm{~W}$ & $0.5-10.5$ & 6.1 & $\mathrm{~W}$ \\
\hline 28 & FP & $3.0-12.0$ & 5.5 & $\mathrm{~W}$ & $0.5-10.5$ & 11.9 & $\mathrm{~A}$ \\
\hline 32 & FP & $3.0-12.0$ & 10.4 & W & $0.5-10.5$ & 11.4 & A \\
\hline 33 & FP & $3.0-12.0$ & 8.2 & $\mathrm{~W}$ & $0.5-10.5$ & 8.0 & $\mathrm{~W}$ \\
\hline 34 & FP & $3.0-12.0$ & 3.8 & $\mathrm{~W}$ & $0.5-10.5$ & 7.3 & $\mathrm{~W}$ \\
\hline 35 & FP & $3.0-12.0$ & 5.9 & $\mathrm{~W}$ & $0.5-10.5$ & 6.9 & $\mathrm{~W}$ \\
\hline
\end{tabular}

Table 2: serum levels of FSH and LH for primary infertile women

\begin{tabular}{|c|c|c|c|c|c|c|c|}
\hline $\begin{array}{l}\text { Patient I.D } \\
\text { number }\end{array}$ & $\begin{array}{l}\text { Cycle } \\
\text { phase }\end{array}$ & $\begin{array}{l}\text { FSH normal range } \\
(\mathrm{ml} / \mu / \mathrm{L})\end{array}$ & $\begin{array}{l}\begin{array}{l}\text { FSH } \\
(\mathrm{ml} \mu / \mathrm{L})\end{array} \\
\end{array}$ & R.INF & $\begin{array}{l}\text { LH normal Range } \\
(\mathrm{ml} \mu / \mathrm{L})\end{array}$ & $\mathrm{LH}(\mathrm{ml} \mu / \mathrm{L})$ & R.INF \\
\hline 01 & $\mathrm{FP}$ & $3.0-12.0$ & 14.3 & A & $0.5-10.5$ & 3.9 & $\mathrm{~W}$ \\
\hline 02 & FP & $3.0-12.0$ & 16.5 & A & $0.5-10.5$ & 5.8 & $\mathrm{~W}$ \\
\hline 03 & FP & $3.0-12.0$ & 9.8 & $\mathrm{~W}$ & $0.5-10.5$ & 4.0 & W \\
\hline 04 & FP & $3.0-12.0$ & 10.3 & $\mathrm{~W}$ & $0.5-10.5$ & 0.8 & $\mathrm{~W}$ \\
\hline 05 & FP & $3.0-12.0$ & 12.8 & $\bar{A}$ & $0.5-10.5$ & 1.2 & $\mathrm{~W}$ \\
\hline 06 & FP & $3.0-12.0$ & 3.4 & $\mathrm{~W}$ & $0.5-10.5$ & 1.2 & W \\
\hline 07 & FP & $3.0-12.0$ & 6.8 & $\mathrm{~W}$ & $0.5-10.5$ & 17.8 & $\mathrm{~A}$ \\
\hline 08 & FP & $3.0-12.0$ & 9.9 & $\mathrm{~W}$ & $0.5-10.5$ & 12.0 & A \\
\hline 09 & FP & $3.0-12.0$ & 13.8 & A & $0.5-10.5$ & 16.3 & $\bar{A}$ \\
\hline 10 & FP & $3.0-12.0$ & 5.2 & $\mathrm{~W}$ & $0.5-10.5$ & 6.9 & $\mathrm{~W}$ \\
\hline 11 & FP & $3.0-12.0$ & 73.9 & $\mathrm{~A}$ & $0.5-10.5$ & 18.0 & $\mathrm{~A}$ \\
\hline 12 & FP & $3.0-12.0$ & 13.0 & $\bar{A}$ & $0.5-10.5$ & 6.2 & $\mathrm{~W}$ \\
\hline 13 & FP & $3.0-12.0$ & 15.5 & A & $0.5-10.5$ & 13.9 & A \\
\hline 14 & FP & $3.0-12.0$ & 7.2 & $\mathrm{~W}$ & $0.5-10.5$ & 9.4 & $\mathrm{~W}$ \\
\hline 15 & FP & $3.0-12.0$ & 14.2 & A & $0.5-10.5$ & 20.1 & $\mathrm{~A}$ \\
\hline 16 & FP & $3.0-12.0$ & 28.1 & $\overline{\mathrm{A}}$ & $0.5-10.5$ & 19.3 & A \\
\hline 17 & FP & $3.0-12.0$ & 3.3 & $\mathrm{~W}$ & $0.5-10.5$ & 9.4 & $\mathrm{~W}$ \\
\hline 18 & FP & $3.0-12.0$ & 2.7 & B & $0.5-10.5$ & 3.7 & $\mathrm{~W}$ \\
\hline 19 & FP & $3.0-12.0$ & 1.4 & B & $0.5-10.5$ & 2.6 & $\mathrm{~W}$ \\
\hline 20 & FP & $3.0-12.0$ & 8.5 & W & $0.5-10.5$ & 4.5 & W \\
\hline 21 & FP & $3.0-12.0$ & 11.4 & W & $0.5-10.5$ & 12.5 & A \\
\hline 22 & FP & $3.0-12.0$ & 7.0 & W & $0.5-10.5$ & 5.8 & W \\
\hline 23 & FP & $3.0-12.0$ & 2.3 & B & $0.5-10.5$ & 11.7 & A \\
\hline 24 & FP & $3.0-12.0$ & 2.7 & B & $0.5-10.5$ & 12.3 & $\mathrm{~A}$ \\
\hline 25 & FP & $3.0-12.0$ & 16.6 & $\mathrm{~A}$ & $0.5-10.5$ & 7.5 & W \\
\hline 26 & FP & $3.0-12.0$ & 17.4 & A & $0.5-10.5$ & 12.2 & $\mathrm{~A}$ \\
\hline 27 & $\mathrm{FP}$ & $3.0-12.0$ & 2.5 & $\mathrm{~B}$ & $0.5-10.5$ & 4.1 & $\mathrm{~W}$ \\
\hline 28 & FP & $3.0-12.0$ & 36.5 & $\mathrm{~A}$ & $0.5-10.5$ & 20.9 & A \\
\hline 29 & FP & $3.0-12.0$ & 6.4 & W & $0.5-10.5$ & 7.1 & W \\
\hline 30 & FP & $3.0-12.0$ & 1.0 & B & $0.5-10.5$ & 0.1 & $\mathrm{~B}$ \\
\hline 31 & FP & $3.0-12.0$ & 7.1 & $\mathrm{~W}$ & $0.5-10.5$ & 8.1 & W \\
\hline 32 & FP & $3.0-12.0$ & 20.4 & $\mathrm{~A}$ & $0.5-10.5$ & 15.4 & $\mathrm{~A}$ \\
\hline 33 & FP & $3.0-12.0$ & 9.0 & W & $0.5-10.5$ & 8.0 & W \\
\hline 34 & FP & $3.0-12.0$ & 11.8 & W & $0.5-10.5$ & 14.8 & A \\
\hline 35 & FP & $3.0-12.0$ & 5.8 & $\mathrm{~W}$ & $0.5-10.5$ & 5.7 & $\mathrm{~W}$ \\
\hline
\end{tabular}

R.INF= Range inference, $\mathrm{B}=$ below normal range, $\mathrm{W}=$ within normal range, $\mathrm{A}=$ above normal range 
Table 3: Hormonal characteristics of control and infertile groups.

\begin{tabular}{lllll}
\hline parameters & $\begin{array}{l}\text { Control group } \\
\mathrm{n}=35\end{array}$ & $\begin{array}{l}\text { Infertile group } \\
\mathrm{n}=35\end{array}$ & t-value & $\mathrm{p}$-value \\
\hline FSH & $7.86 \pm 3.06$ & $12.88 \pm 13.11$ & 0.03 & 0.05 \\
LH & $7.03 \pm 4.01$ & $9.95 \pm 5.97$ & 0.02 & 0.05 \\
\hline
\end{tabular}

Table 3 shows the hormonal characteristics of the control compared to the infertile group. Statistical significant was considered with $\mathrm{p}<0.05$. Serum FSH and LH levels were significantly higher in the infertile group compared to the control group.

Table 4: comparison between observed values in FSH and LH

\begin{tabular}{|l|l|l|l|}
\hline parameter & Values below normal range (\%) & Values within normal range (\%) & Values above normal range (\%) \\
\hline FSH & 17.14 & 45.71 & 37.14 \\
\hline LH & 2.86 & 57.14 & 40 \\
\hline
\end{tabular}

Table 4 shows the comparison between the observed values in FSH and LH in the infertile group, so as to derive an inference on the physiological relationship between the two gonadotropins.

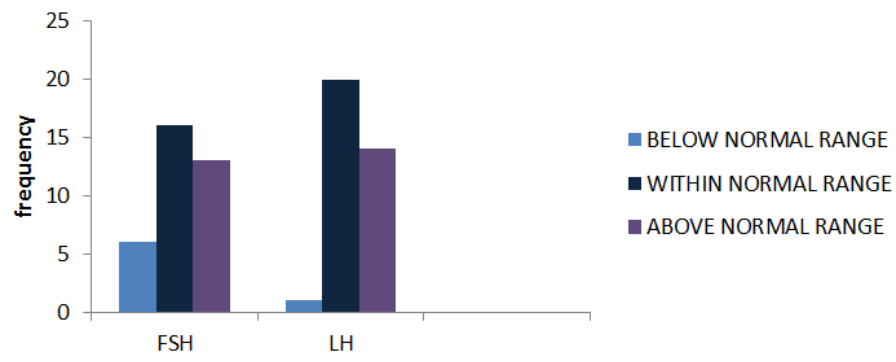

Figure 1: FSH, LH frequency of range values for primary infertile women

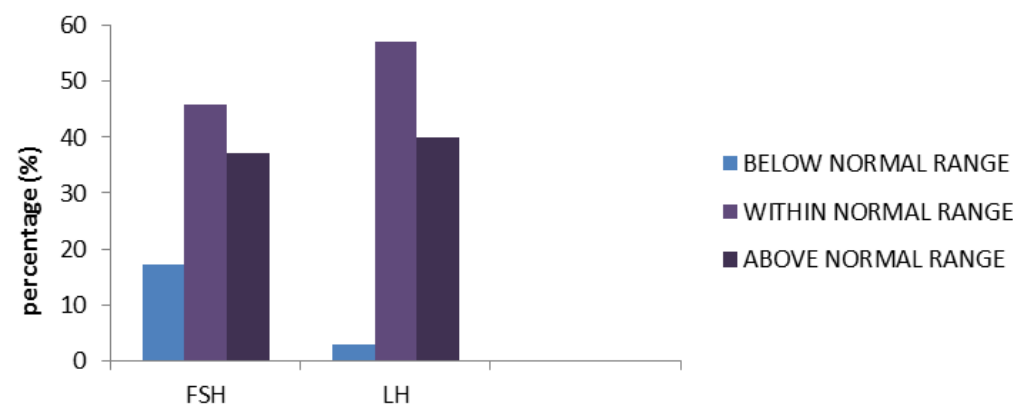

Figure 2: FSH, LH Percentage frequency of range values for primary infertile women

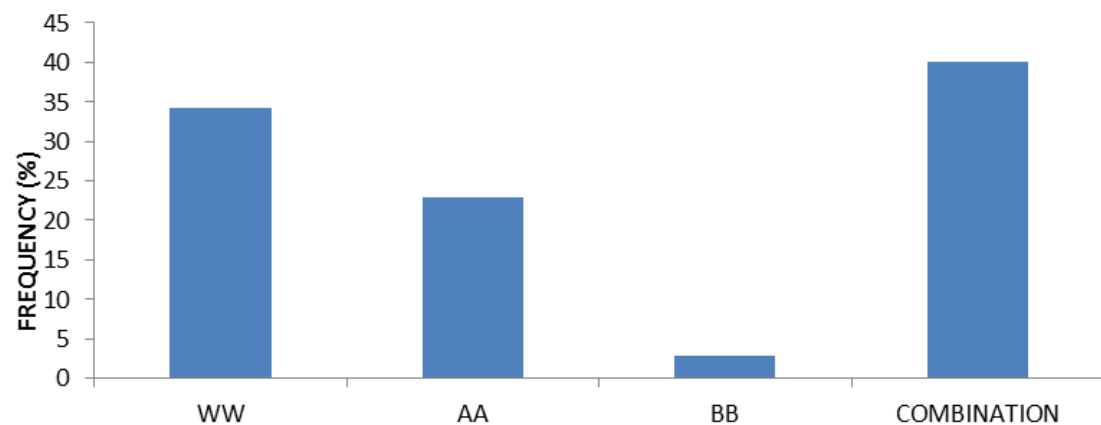

Figure 3: correlation between FSH and LH values.

Fig. 3 above shows the percentage correlation between the FSH and LH serum levels amongst the infertile women studied. WW indicates where both serum levels of FSH and LH are within the normal limits in the same patient. AA represents cases where both serum levels of the two hormones are above the normal limits and $\mathrm{BB}$ represents the cases where the serum levels of the two hormones are below the normal range limits in the same patient. 


\section{Discussion}

When the FSH serum levels of the infertile women are compared to that of the control group statistically, it shows a statistically significantly higher serum FSH $[\mathrm{FSH}$ mean $\pm \mathrm{SD}, 12.88 \pm 13.11(\mathrm{p}<0.05)]$ in the infertile group than the control group. LH serum levels is higher in the infertile group than in the control group as well $[$ mean \pm SD 9.95 $\pm 5.97(p<0.05)] .17 .14 \%$ had FSH serum levels below (B) the normal range of expected values, $45.71 \%$ had serum levels within (W) normal range, and $37.14 \%$ had serum levels above (A) the normal range of expected values. For LH, $2.86 \%$ had LH serum levels below the normal range of expected values, $57.14 \%$ had serum levels within normal range, and $40 \%$ had serum levels above the normal range of expected values. Analysis of the physiological correlation between FSH and LH values for the infertile group shows that they are significantly correlated, $r=0.53, p<0.01 .34 .3 \%$ of the patients had both serum levels of FSH and LH within the normal limits (3.0-12.0 and 0.5-10.5 ml $\mu / \mathrm{L}$ respectively).In $2.9 \%$ of the cases, both FSH and LH serum levels are below the normal range of expected values (2.9\%).

A serum level of FSH below the normal range limits $(3.0-12.0 \mathrm{ml} / \mathrm{L})$ and $\mathrm{LH}(0.5-10.5 \mathrm{ml} / \mathrm{L})$ during the follicular phase indicates that defect in factors that are responsible for their production could be responsible and which will lead to a poor ovarian reserve and can cause infertility. These factors could be as a result of defects in the pituitary gland, GnRH or the hypothalamus [11]. On the other hand, FSH and LH values above the normal limits suggests a problem arising from another component of the reproductive system, probably a defect in the negative feedback regulation mechanism in the hypothalamus by estrogen and progesterone [12]. Table 4 and Fig. 2 show a common pattern between FSH and LH levels, having values within (W) the normal range limits recording the highest frequency, values above (A) normal limits ranking second in frequency and values below (B) normal limits being the lowest. This result suggests a physiological correlation that expresses a direct proportionality between FSH and LH. This shows that the cause of infertility arising from abnormal serum levels of FSH and LH may be due to a factor that has effect on or regulate the functions of these two hormones. This suggests that the abnormality could be associated with GnRH, which controls both FSH and LH production, the pituitary gland which is responsible for the production of FSH and LH, and the hypothalamus which is the control center for GnRH [13]. Fig. 3 explains the correlation between FSH and LH values, in 34.3\% of the cases, the patient has both serum levels of FSH and LH within the normal limits $(3.0-12.0 \mathrm{ml} \mu / \mathrm{L}$ and 0.5 $10.5 \mathrm{ml} / \mathrm{L}$ respectively). This suggests that the cause of infertility is due to other factors such as damage to the ovary, viral infection, chemotherapy, drugs, and other hormonal abnormalities with estrogen and progesterone that are responsible for development of the endometriun and also unexplained infertility could be the factor [6]. Possibilities of luteal phase defects cannot be ruled out even if the serum levels of the two hormones appear to be within normal limits in the follicular phase. According to [14], 65.5\% of infertile women with proper menstrual cycles suffered from luteal phase defect. Hyperprolactinemia could also be a dominant cause of infertility in females. The incidence of hyperprolactinemia was reported to be $42.9 \%$ by [15], 25\% by [16]. [17] stated that women with higher values of prolactin and luteal phase defects have lower serum levels of FSH and LH during their menstrual cycle. In Fig. 3, Cases where both FSH and LH serum levels are low (2.9\%) suggests cause of infertility to be due to a defect in the negative feedback of estrogen and progesterone on GnRH [18].

\section{Conclusion}

In women where there was an elevated or a decreased FSH and LH values clearly show that there is a mechanism operating at the anterior pituitary gland which shows an abnormal distribution of FSH and LH, which may further explains it to be a possible cause of the infertility due to abnormal or delayed ovum maturation. Cases where the serum levels of these hormones are within the normal limits clearly show that the cause of infertility is due to other factors outside FSH and LH, but could still be hormonal or otherwise. The observed statistically significant increasein FSH and LH in this study could be due to elevated prolactin serum level in infertile women as compared to the control and this may be responsible for the infertility observed in these set of women. Further studies may be to assess the prolactin status of infertile women to ascertain the effect of hypreprolactinemia on infertility. Also, estrogen and progesterone serum levels should be investigated to ascertain the status of feedback inhibition on GnRH production in infertile women. Magnetic resonance imaging (MRI) should be an additional investigative procedure to completely diagnose cause of infertility as this will detect pituitary tumors that could be responsible for hormonal defects. It could be concluded on the physiological correlation between FSH and LH, as evident in the correlation result that, in cases where the two hormones express the same pattern of behavior, the factor responsible for infertility is a factor that controls or has a direct influence on the production and function of these two gonadotropins. This then suggest GnRH, pituitary and hypothalamic defects.

\section{Acknowledgment}

The authors would like to thanks to University of Jos teaching Hospital (JUTH), for technical support and making patients available for the successful completion of this research work. 


\section{References}

[1] R. S. Maker, and T.L. Toth, The evaluation of infertility, American Journal of Clinical Pathology, 117, 2002, 95-103

[2] A. D. Domar, D. Clapp, E. Slawsby, B. Kessel, J. Orav, and M. Freizinger, The impact of group psychological interventions on distress in infertile women, Health Psychology, 19(6), 2000, 568-575.

[3] K. Kaushal, and S. M. Shalet, Defining growth hormone status in adults with hypopituitarism, Hormonal Research, 68 (4), 2007, 185-94.

[4] J. Sciarra, Infertility: An international health problem, International Journal of Gynecology and Obstetrics, 46, 1994, 155-163.

[5] R. P. G. ten Broek, N. Kok-Krant, H. R. Verhoeve, H. van Goor, and E. A. Bakkum, Efficacy of polyethylene glycol adhesion barrier after gynecological laparoscopic surgery: Results of a randomized controlled pilot study, Gynecological Surgery, 9, 2002, 29-35.

[6] Z. Roupa, M. Polikandrioti,P. Sotiropoulou, E. Faros, A. Koulouri,G. Wozniak, and M. Gourni, Causes of infertility in women at reproductive age, Health Science Journal, 3(2), 2009, 80-87.

[7] I. T. Huhtaniemi, and A. P. Themmen, Mutations in human gonadotropin and gonadotropin-receptor genes, Endocrine,26, 2005, $207-217$.

[8] E. A. McGee, and A. J. Hsueh, Initial and cyclic recruitment of ovarian follicles. Endocrine Reviews, 21, $2000,200-214$.

[9] U. Larsen, G. Masenga and J. Mlay, Infertility in a community and clinic-based sample of couples in Moshi, northern Tanzania, East African Medical Journal, 83, 2006, 10-17.

[10] W. D. Odell, and A.F. Parlow, Estimation of FSH test assay, Journal of ClinicalInvestigation, 47, 1981, $25-51$.

[11] S. Nussey, and S. Whitehead, Endocrinology: an integrated approach (Oxford, BIOS Scientific Publishers, 2001)

[12]. H. A. David, P. Vasantha, and A. D. Daniel, Contributions of androgen and estrogen to fetal programming of ovarian dysfunction, Reproductive Biology and Endocrinology, 4, 2006, 17.

[13]. A. Nemeskéri, A. Detta, R. N. Clayton, Hypothalamic GnRH and pituitary gonadotroph relationships during rat fetal life, Experimental Clinical Endocrinology, 88(3), 1986, 275-284.

[14]. L. Moltz, F. Leidenberger, and C. Weise, Rational hormone diagnosis in normocyclic functional sterility. Journalof Infertility, 51(9), 1991, 756-768.

[15]. K. Mohan, and S. Mazher, Follicle stimulating hormone, luteinizing hormone and prolactin levels in infertile women in north chennai, tamilnadu, Journal of Biological science Research, 1(4), 2010, 279-284.

[16]. R. Mishra, R. Baveja, V. Gupta, Prolactin level in infertility with menstrual irregularities. The Journal ofObstetrics and Gynecology in India, 52, 2002, 40-43.

[17]. J. R. Givens, P.O. Kohler, and W. John, Ovarian disorders, clinical endocrinology (New York, 1986).

[18]. P. Bouchard, J. P. Wolf, and S. Hajri, Inhibition of ovulation: comparison between the mechanism of action of steroids and GnRH analogues, Human Reproduction,3(4), 1988, 503-506. 